\title{
A STUDY OF THE ANTHOCYANINS OF KENAF
}

Z. B. Rakhimkhanov, A. S. Sadykov, A. I. Ismailov, and A. K. Karimdzhanov

Khimiya Prirodnykh Soedinenii, Vol. 6, No. 1, pp. 129-130, 1970

UDC $547.972 / 73$

Continuing a study of the anthocyanins [1] of the family Malvaceae, by partition chromatography on a column of cellulose powder [in the water-acetic acid $(85: 15)$ system] we have isolated from the flowers of Hibiscus cannabinus var. simplex (kenaf) collected in the experimental section of the central Asian Branch of VIR [All-Union Scientific Research Institute for Plant Breeding] an anthocyanin with $\mathrm{mp} 164-166^{\circ} \mathrm{C}$ (decomp.) having the composition $\mathrm{C}_{26} \mathrm{H}_{29} \mathrm{O}_{16} \mathrm{Cl} \cdot 4 \mathrm{H}_{2} \mathrm{O}$.

Hydrolysis with a $2 \mathrm{~N}$ solution of $\mathrm{HCl}$ and with the enzyme of Aspergillus oryzae led to the decomposition of the anthocyanin into an aglycone, glucose, and xylose. On stepwise acid hydrolysis, paper chromatography showed the production of a monoglycoside of delphinidin.

The sugar moiety of the anthocyanin was identified by paper chromatography in several systems in the presence of markers and by the preparation of ozazones. The results of measurements of the UV spectrum of the glycoside showed the presence of free hydroxyl groups in its side chain ( $\lambda_{\max } 531 \mathrm{~m} \mu$ without additives and $\lambda_{\max } 576 \mathrm{~m} \mu$ with the addition of $5 \%$ of aluminum chloride in ethanol).

When the glycoside was oxidized with $30 \%$ hydrogen peroxide in the presence of ammonia, a bioside was detected the subsequent hydrolysis of which with $2 \mathrm{~N} \mathrm{HCl}$ for $10 \mathrm{~min}$ gave glucose and xylose. The sugars were identified by a previously-published method [2].

The identity of the aglycone with delphinidin was confirmed by the results of a chromatographic comparison of it with the delphinidin obtained from Solanum melongena L. (eggplant) and by measuring the absorption spectra ( $\lambda_{\text {max }}$ $545 \mathrm{~m} \mu)$.

The cleavage of the anthocyanidin with $15 \%$ barium hydroxide for $30 \mathrm{~min}$ at $100^{\circ} \mathrm{C}$ led to the formation of phloroglucinol and gallic acid. The latter was identified by paper chromatography in the presence of reference materials.

On the basis of the results given above, the glycoside isolated from the kenaf flowers was identified as a new anthocyanin, delphinidin $3-0-\beta-\mathrm{D}-$ glycosyl- $\beta-\mathrm{D}-\mathrm{xyloside,} \mathrm{which} \mathrm{we} \mathrm{have} \mathrm{called} \mathrm{"cannabinidin;"}$

A quantitative determination of the anthocyanin in four species of Hibiscus was carried out on an SF-4A spectrophotometer. The amounts of the anthocyanin were $(\%)$ : in Hibiscus cannabinus var. simplex 5.8 in the flowers, 0.8 in the leaves, and 0.5 in the stems; in Hibiscus cannabinus var. purpureus: 4.7 in the flowers, 0.9 in the leaves, and 0.7 in the stems; in Hibiscus cannabinus var. vulgare: 1.5 ; and in Hibiscus cannabinus v. viridis 1.8 .

\section{REFER EN C ES}

1. Z. B. Rakhimkhanov, A. K. Karimdzhanov, A. I. Ismailov, and A. S. Sadykov, KhPS [Chemistry of Natural Compounds], 4, 190, 1968.

2. A. S. Sadykov, Z. B. Rakhimkhanov, A. I. Ismailov, and A. K. Karimdzhanov, Nauchnye tr. TashGU, 3, no. $341,72,1968$.

\section{October 1969}

Scientific-Research Institute for the Chemistry and Technology of Cotton Cellulose, Tashkent 